\section{Development and Characteri- zation of Chitosan-Nanoclay Composite Films for Enhanced Gas Barrier and Mechanical Properties}

\section{Marcos A Neves ${ }^{1,2 *}$, Jafar Hashemi $i^{1,3}$, Tomoyuki Yoshino ${ }^{4}$, Kunihiko Uemura ${ }^{2}$ and Mitsutoshi Nakajima ${ }^{1}$}

${ }^{1}$ Department of Life and Environmental Sciences, University of Tsukuba, Tennoudai, Tsukuba, Ibaraki, Japan

${ }^{2}$ Division of Food Engineering, National Food Research Institute, Kannondai, Tsukuba, Ibaraki, Japan

${ }^{3}$ JASSO Follow-up Researcher, Sari Agricultural Sciences and Natural Resources University, Iran

${ }^{4}$ Department of Life and Environmental Sciences, Prefectural University of Hiroshima, Ujina-Higashi, Minami-ku, Hiroshima City, Hiroshima Prefecture, Japan

\begin{abstract}
Chitosan-nanoclay composite films were investigated in this study, aiming to develop films with enhanced mechanical properties, and high-barrier against gas exchange, foreseeing their application as base material for food packaging. The effect of nanoclay concentration on the Water Vapor Permeability (WVP), Water Vapor Transmission (WVTR), mechanical properties and morphology of surface structure of the composite films were evaluated. Chitosan-based composite films were prepared using a solvent-casting method, also incorporating of bentonite nanoclay in the filmogenic mixture. As for the results obtained, nanoclay concentration greatly affected the WVP of the casted composite films. The lowest WVTR was observed in films consisting of $2 \mathrm{wt} \%$ chitosan and $3 \mathrm{wt} \%$ nanoclay. By adding up to $3 w t \%$ bentonite nanoclay, the Tensile Strength (TS) of the composite films could be enhanced up to $60 \%$, as comparted to films prepared using $2 \mathrm{wt} \%$ chitosan alone. Seemingly, the elongation of composite films decreased with increasing nanoclay content. Moreover, the combination of nanoclay $3 w t \%$ and chitosan $2 w t \%$ resulted in more resistant films (higher TS) and with reduced gas transfer (lower WVP) and Elongation (E). The results suggest that films containing $3 \%$ nanoclay not only decreased the WVP by aiding the role of chitosan, but also modified
\end{abstract}

*Corresponding author: Marcos A Neves, Department of Life and Environmental Sciences, University of Tsukuba, 1-1-1 Tennoudai, Tsukuba, Ibaraki 3058572, Japan, Tel: +81 298536763; E-mail: marcos.neves.ga@u.tsukuba.ac.jp

Citation: Neves MA, Hashemi J, Yoshino T, Uemura K, Nakajima M (2016) Development and Characterization of Chitosan-Nanoclay Composite Films for Enhanced Gas Barrier and Mechanical Properties. J Food Sci Nutr 2: 007.

Received: January 15, 2016; Accepted: March 10, 2016; Published: March 25, 2016 the rheological properties of resulting film. Therefore, the combination of chitosan and nanoclay may lead to the formation of novel composite films with enhanced mechanical properties and selective gas barrier, a promising material for food packaging applications.

Keywords: Bentonite nanoclay; Chitosan; Composite film; Gas barrier; Rheology

\section{Introduction}

The steady increase in world population within the past decades, associated with an increasing demand for high quality foods with prolonged shelf-life, and environmental issues relating to the scarce natural resources, the use of renewable resources to produce edible or biodegradable packaging materials is on high demand [1]. Edible films and coatings have received considerable attention in recent years, because of their advantages over synthetic films. The biopolymers are usually derived from different renewable natural resources such as carbohydrates and proteins [2]. Polysaccharides used for producing edible films include cellulose, starch derivatives, pectin derivatives, seaweed extracts, microbial fermentation gums and chitosan [3].

Biodegradable materials made from natural resources, especially those based on starch, have attracted worldwide interest and a desire to expand their nonfood use, partially due to their low cost. In spite of receiving much interest, starch-based materials have failed to gain widespread use because they deteriorate too easily when subjected to a high-moisture environment [4]. Among the active biomolecules, chitosan has a great potential for a wide range of food applications due to its biodegradability, biocompatibility, antimicrobial activity, non-toxicity and film-forming capacity [5-7]. It can form semi-permeable coatings, which can modify the internal atmosphere, there by delaying ripening and decreasing transpiration rates in fruits and vegetables [8]. Chitosan biopolymer has several advantages over other types of disinfectants and synthesis polymer such as biodegradability, gas barrier (increasing shelf life), and antimicrobial (increasing of spoilage time).

The increasing demand for minimally processed agricultural products with extended storage stability and minimum loss in nutritional quality, whether it is during processing, transport or storage, edible films and coatings have increasingly received a great deal of attention in recent years, considering their advantages over synthetic films [2]. To design proper edible antimicrobial films to be used in food preservation can be considered as one of the major challenges for food technologists in the next few years [9]. In the future, these films will be tailor-made aiming to solve specific issues related to catering and/or storage conditions, for a given food product.

A new trend in food preservation consists of the use of active packaging, foreseeing enhanced safety margin and reassure high quality products and the incorporation of antimicrobial agents in films, which can be used as active packaging [10]. Films and coatings with antimicrobial properties have innovated the concept of active packaging, being developed to reduce, inhibit or stop the growth of microorganisms on food surfaces $[11,12]$. In fact, packaging films incorporated with antimicrobial substances, are of great potential for 
food preservation due to their antiseptic properties and conveniences for food [13]. This kind of materials are considered as one of the most promising active packaging systems, as they are highly effective in killing or inhibiting spoilage and pathogenic microorganisms that contaminate food, and can limit the possible undesirable flavors that are caused by the direct addition of active compounds into foods [14]. In these regards, Kim et al., [15] reported about the antimicrobial activity attributed to chitosan, which is likely originated from its polycationic nature. More recently, Elsabee and Adbpu [16] suggested that the antimicrobial action of chitosan may be mediated by the electrostatic forces between the protonated amino group $\left(\mathrm{NH}_{2}\right)$ in chitosan and the negative residues at cell surfaces.

Nevertheless, films prepared with pure chitosan-based films do not provide satisfactory functionality due to lack of mechanical properties and water resistance. Thus, composite films based on chitosan reinforced with other material, such as nanoparticles, have been receiving a great deal of attention. The use of nanoparticles in these polymer matrices, thus creating a composite, can yield an optimal multi-functional material for aerospace needs and other applications [17]. Casariego et al., [18] have investigated about the development of chitosan-based films, as affected by the addition of clay nanoparticles. In that study, the authors used chitosan having a degree of deacetylation of $90 \%$ and lactic acid as solvent. Those authors were able to improve the water vapor barrier properties of the films, by incorporating clay in the film composition. Nevertheless, chitosan chains with higher degree of deacetylation may facilitate the hydrogen bond formation, and consequently crystallinity formation in the film [19]. Consequently, films based on chitosan with higher degree of deacetylation may have loosen mechanical properties, such as lower elongation. For this reason, the authors have endeavored this research using chitosan with a lower degree of acetylation (75\%) dissolved in a different solvent (acetic acid), foreseeing enhanced mechanical properties for the films casted here.

Nevertheless, concerns about the low mechanical properties of chitosan-based films have been raised, such as the considerably high water vapor permeability [20], and low thermal stability. One of the promising ways to modify biopolymer properties such as inherent water sensitivity, relatively low stiffness and strength, and low thermal stability, is to make hybrid films with biopolymers and nano sized materials, which are known as composite films. These films are generally composed of silicates and organic polymers disposed in the form of layers on micro/nanometer size range, and have increasingly called the attention of researchers from different fields, such as materials science, or food packaging. For instance, edible covers with nanoclays can extend the shelf life and improve the quality of fruits by providing barriers to mass transfer, improving integrity or handling and/or the functional loads such as antimicrobial agents and antioxidants [11]. On these regards, the objectives of this study were to prepare chitosan-based films reinforced with bentonite nanoclay, aiming to improve their mechanical properties, and to enhance their barrier ability against gas exchange. We also evaluated the microstructure morphology of the different composite films prepared, foreseeing their potential application as base material for food packaging.

\section{Materials and Methods}

\section{Materials}

Chitosan (CAS: 9012-76-4; Product code 448877; Sigma-Aldrich, Japan) having deacetylation degree of $75 \%$, medium molecular weight $(50,000 \mathrm{~g} / \mathrm{mol})$, and viscosity of $200-800 \mathrm{cps}$ ( $1 \mathrm{wt} \%$ solution).
Nanoclay (CAS: 1302-78-9, Nanomer ${ }^{\circledast}$ clay, Sigma-Aldrich, USA), also known as hydrophilic bentonite or Montmorillonite clay, consisting of nearly $1 \mathrm{~nm}$-thick layers stacked in multilayer of 5-10 $\mu \mathrm{m}$ (information provided by the manufacturer). Glycerol, Tween 20 (Polyoxyethylene (20) sorbitan monolaurate) and all other reagents used in this study were of analytical grade purchased from Wako Pure Chemical Ind. Ltd. (Osaka, Japan). The water used was filtered deionized water (Milli-Q water).

\section{Preparation of composite films by casting technique}

The flowchart of the process used in this study to prepare composite films is depicted in figure 1.

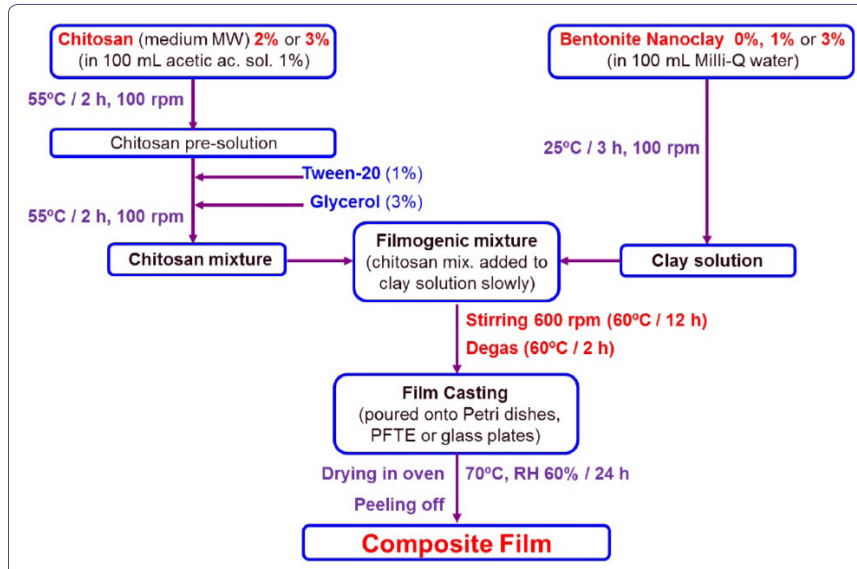

Figure 1: Flowchart of the process used to prepare composite films by casting technique.

Chitosan aqueous solutions (containing either 2 or $3 \mathrm{wt} \%$ ) were initially prepared by dissolving appropriate amounts of chitosan in $100 \mathrm{~g}$ of acetic acid aqueous solution (1wt\%), followed by gently mixing on a magnetic stirrer $(100 \mathrm{rpm})$ for $2 \mathrm{~h}$ at $55^{\circ} \mathrm{C}$ for complete dissolution. On the sequence, glycerol was added (3wt\%) as plasticizer, and Tween 20 was used (1wt\%) as stabilizer, and this chitosan pre-mixture was stirred for $2 \mathrm{~h}$ at $55^{\circ} \mathrm{C}$. On the other hand, nanoclay dispersions (containing either 1 or $3 \mathrm{wt} \%$ ) were prepared by adding appropriate amounts of Nanomer ${ }^{\oplus}$ to $100 \mathrm{~mL}$ of Milli-Q water, and stirring for $3 \mathrm{~h}$ at room temperature. After preparing the chitosan pre-mixture and nanoclay dispersion separately, the chitosan solution was slowly added to the nanoclay dispersion and mixed vigorously by magnetic stirrer $(600 \mathrm{rpm})$ for $12 \mathrm{~h}$ at $55^{\circ} \mathrm{C}$. In order to remove air bubbles from the filmogenic mixture, the samples were degassed for $2 \mathrm{~h}$ [21]. The filmogenic mixtures consisting of chitosan and bentonite nanoclay were poured onto different materials, and the films were formed by casting technique [11]. As indicated in figure 2, the following support materials were used for casting the composite films: smooth polyethylene sheet $\left(10 \times 20 \mathrm{~cm}^{2}\right)$; aluminum plate $\left(10 \times 13 \mathrm{~cm}^{2}\right)$; glass plate $(\phi=16 \mathrm{~cm})$.

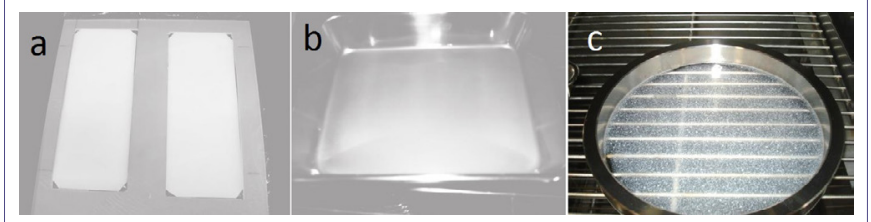

Figure 2: Casting support materials used to prepare the composite films: a) Smooth polyethylene sheet $\left(10 \times 20 \mathrm{~cm}^{2}\right) ;$ b) Aluminum plate $\left.\left(10 \times 13 \mathrm{~cm}^{2}\right) ; \mathrm{c}\right)$ Glass plate $(\phi=16 \mathrm{~cm})$.

After pouring appropriate amounts of the filmogenic mixture onto each casting support, in order to obtain the desirable minimum film 
thickness, the plates were kept at $70^{\circ} \mathrm{C}$ for $24 \mathrm{~h}$ in a convection oven. The relative humidity measured here was around $60 \%$, which is similar to that previously reported [21]. The composite films formed were then peeled intact from the plate surface, as depicted in figure 3. After drying, the composite films were kept in a desiccator at room temperature, prior to use.

In order to indicate the different compositions of chitosan-nanoclay used in each case, film codes were used to identify the samples. The codes were generated as indicated in the vertical box below:

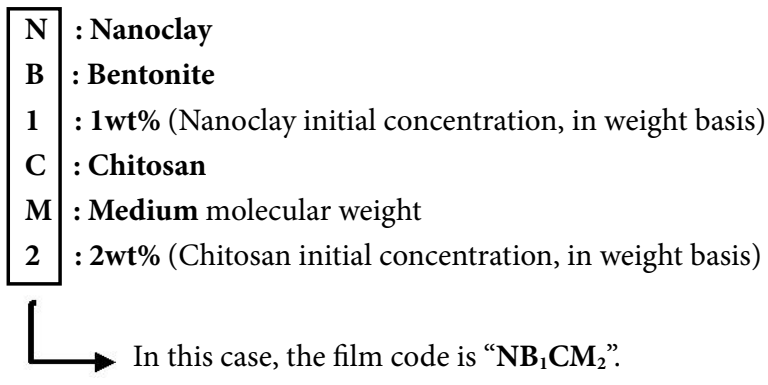

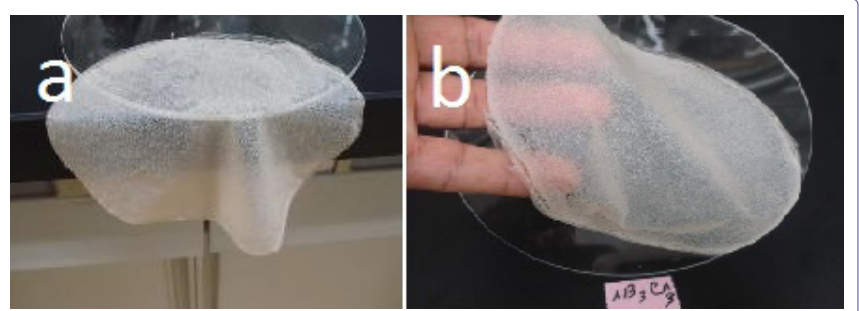

Figure 3: Peeling off composite films from a glass plate. The film composition was nanoclay $3 w t \%$ and chitosan $3 w t \%$ (film code: $\mathrm{NB}_{3} \mathrm{CM}_{3}$ ).

\section{Analyses}

The $\mathrm{pH}$ of filmogenic mixture was measured using a $\mathrm{pH}$-meter (Metrohm, $827 \mathrm{pH} \mathrm{lab,} \mathrm{Swiss)} \mathrm{at} 25^{\circ} \mathrm{C}$. The films thickness was measured using a digital slide caliper by reading accurately at different area of films with three repetitions, and the average thickness was computed.

In order to elucidate the water sorption behavior and gas exchange properties of the films prepared, the Water Vapor Permeability (WVP) was measured by using the Japanese standard method JIS K7129 [22]. Cups consisting of cylindrical shape $(\phi=7 \mathrm{~cm}$; depth=2.1 cm) and a cover ring for sealing. Cups were filled with $\mathrm{CaCl}_{2}$ (nearly $12 \mathrm{~g}$ ), covered with a certain composite film sample cut into discs $(\phi=7 \mathrm{~cm})$, sealed with paraffin and placed in a desiccator chamber conditioned with relative humidity $70 \%$, kept at $37^{\circ} \mathrm{C}$. The weight of each cup was measured periodically (every $12 \mathrm{~h}$ ) up to $48 \mathrm{~h}$. The WVP of the composite films was calculated using equation 1 , as indicated below:

$$
W V P=\frac{W L}{t A P}
$$

where:

WVP=Water Vapor Permeability $\left(10^{-12} \mathrm{~g} \cdot \mathrm{m} / \mathrm{m}^{2} \cdot \mathrm{s} \cdot \mathrm{Pa}\right)$,

$\mathrm{W}=$ Increase in cup weight $(\mathrm{g})$,

$\mathrm{L}=$ Thickness of film (m),

$\mathrm{t}=$ Measurement time $(\mathrm{s})$,

$\mathrm{A}=$ Composite film sample area $\left(0.048 \mathrm{~m}^{2}\right)$, and

$\mathrm{P}=$ Pressure difference between outside and inside the cup $(\mathrm{Pa})$.

During this experiment, the weight change of the cups versus time was recorded and plotted. The slopes of the steady state period of the curves of weight loss as a function of time indicates the Water Vapor Transmission Rate (WVTR) [22,23], which was calculated using the equation 2, as follows:

$$
W V T R=\frac{W_{1}-W_{2}}{t A}
$$

The Tensile Strength (TS) was measured using a rheometer (Model DC V, Shiba Soko, Japan). For this purpose, each sample of the casted films was cut using a standard sample cutter (JIS Z1702; Rheotech, Tokyo, Japan), and the TS of each film sample was measured by loading them with a constant pulling rate of $2 \mathrm{~cm} / \mathrm{min}$ at, room temperature. TS of all samples was expressed in MPa.

Elongation at break point (E) of the samples was calculated using equation 3 , as indicated below:

$$
E=\frac{L_{r}-L_{0}}{L_{0}} \mathrm{X} 100
$$

where:

$\mathrm{L}_{0}=$ Initial film length

$\mathrm{L}_{\mathrm{r}}=$ Final film length at the break point (where film rupture occurred). (\%).

The values indicating $\mathrm{E}$ of all samples were expressed as percentage

The microstructure of pure nanoclay, the surface and cross-section morphologies of the films prepared were investigated as follows: nearly $5 \times 5 \mathrm{~mm}^{2}$ of each film sample was mounted onto a stub using double-sided adhesive carbon tape, and observed using a bench-top scanning electron microscope, SEM (Hitachi Miniscope TM-1000, Tokyo, Japan) at an acceleration voltage of $15 \mathrm{kV}$. All the analyses were repeated five times for each type of film.

\section{Results and Discussion}

The morphology of Nanomer ${ }^{\circledast}$ particles used in this study was investigated. As indicated in figure 4, individual clay particles having around 10 to $20 \mu \mathrm{m}$ consists of multilayer stacks of around $5-10 \mu \mathrm{m}$, indicated by black arrows on the left-side micrograph.

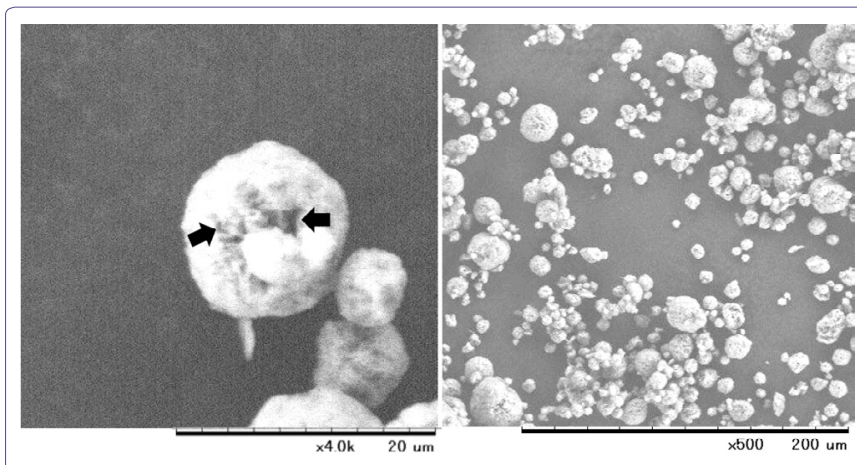

Figure 4: Morphology of bentonite clay analyzed by scanning electron microscopy.

The film codes used for each chitosan-nanoclay composition, the thickness of the films obtained, as well as the WVTR were calculated and presented in table 1.

In general, increasing chitosan and/or nanoclay contents results in increased thickness, for all films prepared. Moreover, the presence of nanoclay, even at a minimum concentration $(1 \mathrm{wt} \%)$, resulted in considerably thicker films, which was expectable and may be 
- Page 4 of 7 •

\begin{tabular}{|c|c|c|c|c|c|c|c|}
\hline & & $\begin{array}{l}\text { Bentonite nanoclay } \\
\text { (wt } \%)\end{array}$ & $\mathrm{pH}$ of mixture & Film code* & Film thickness $(\mu \mathrm{m})$ & Film weight $(\mathrm{g})^{\star *}$ & $\operatorname{WVTR}^{\star * *}\left(\mathrm{~g} /\left(\mathrm{m}^{2} \bullet \mathrm{h}\right)\right)$ \\
\hline \multirow{6}{*}{$\begin{array}{c}\text { Chitosan } \\
\text { (wt\%) }\end{array}$} & \multirow{3}{*}{2} & & 4.7 & NB0CM2 & 47.7 & 0.37 & 1.69 \\
\hline & & 1 & 4. 45 & NB1CM2 & 60.3 & 0.44 & 1.3 \\
\hline & & 3 & 4.44 & NB3CM2 & 62.5 & 0.51 & 0.47 \\
\hline & \multirow{3}{*}{3} & 0 & 4.67 & NB0CM3 & 52.6 & 0.47 & 1.16 \\
\hline & & 1 & 4.96 & NB1CM3 & 65.5 & 0.48 & 1.3 \\
\hline & & 3 & 4.32 & NB3CM3 & 69.5 & 0.9 & 0.9 \\
\hline
\end{tabular}

Table 1: Properties of the different chitosan-nanoclay composite films prepared in this study.

* The film codes are described at figure 5 caption.

** Initial weight of composite film samples cut into discs $(\phi=7 \mathrm{~cm})$, prior to WVP measurement

*** WVTR: the water vapor transmission rate

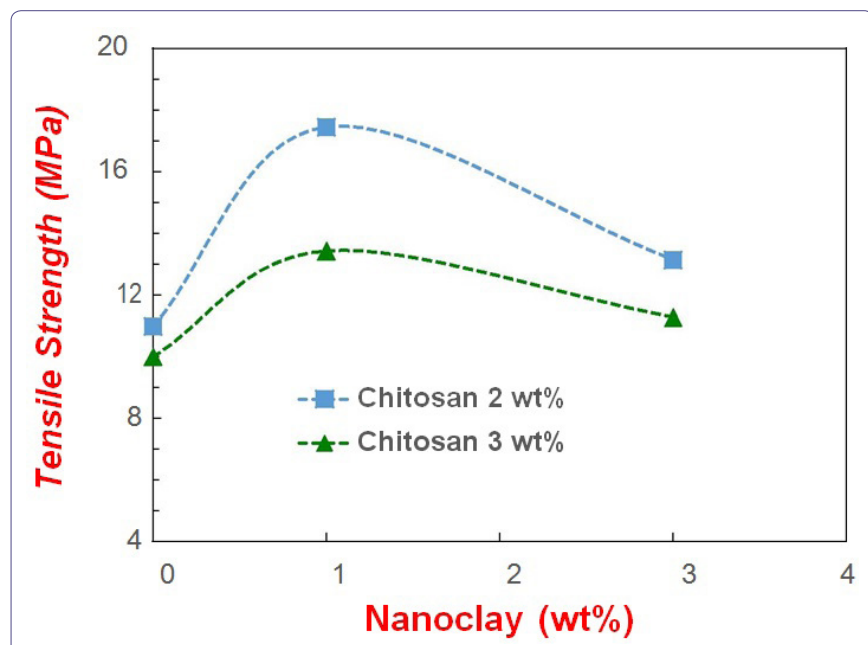

Figure 5: Tensile strength of the composite films prepared using various levels of chitosan and bentonite nanoclay.

explained by the higher bulk density of bentonite nanoclay particles, compared to chitosan.

\section{Water Vapor Permeability (WVP)}

As indicated in figure 6, the films prepared using either 2 or $3 \mathrm{wt} \%$ chitosan ( $0 \%$ nanoclay), had WVP values between $18.6 \times 10^{-12}$ and $16.1 \times 10^{-12}$ g.m $/\left(\mathrm{m}^{2}\right.$.s.Pa), respectively. The WVP values obtained in this study are similar to those reported in our previous study, where biodegradable films based on zein, a hydrophilic protein from maize, had the lowest WVP of $12 \times 10^{-12} \mathrm{~g} . \mathrm{m} /\left(\mathrm{m}^{2} . \mathrm{s} . P a\right)$ [22]. Upon addition of nanoclay, in case of films containing $2 \mathrm{wt} \%$ chitosan the WVP could be effectively reduced, and this decrease was inversely proportional $\left(\mathrm{R}^{2}=0.99\right)$ to the concentration of bentonite nanoclay (Figure 6, top), as given by equation 4 :

$$
\mathrm{WVP}=18.614-3.357 \times \text { Nanoclay }
$$

where:

WVP=Water Vapor Permeability $\left(10^{-12} \mathrm{~g} \cdot \mathrm{m} / \mathrm{m}^{2} \cdot \mathrm{s} \cdot \mathrm{Pa}\right)$,

Nanoclay $=$ Bentonite nanoclay concentration $(\mathrm{wt} \%)$

In fact, the addition of 1 or $3 \mathrm{wt} \%$ nanoclay to the chitosan pre-mixture resulted in between $18 \%$ to $54 \%$ reduction on WVP respectively, as compared to films prepared using $2 \mathrm{wt} \%$ chitosan alone. These results indicated that various concentrations of nanoclay greatly affect the WVP of biopolymer films at certain concentration of chitosan, which may be due to the fulfilling of interspaces in the chitosan matrix by nanoclay particles, conferring higher gas barrier properties to the films formed. Such interspaces in chitosan matrix have also been reported in previous literature [24].

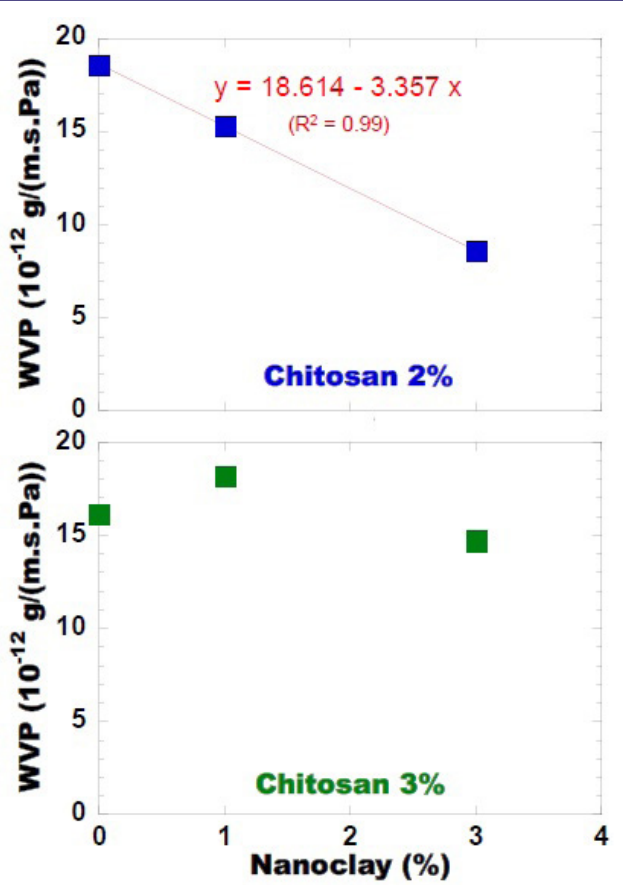

Figure 6: Water Vapor Permeability (WVP) of the composite biopolymer-based films.

The above results demonstrate that the gas barrier property of composite films can be modulated by tuning the film composition, especially regarding the exchange of water vapor. These results are similar to those obtained by Hale and Funda [25].

\section{Water Vapor Transmission Rate (WVTR)}

On the other hand, apparently these were no direct effect of film composition on WVTR, as indicated in table 1. For instance, at intermediate nanoclay content (1wt\%) in the composite films, similar WVTR values were obtained regardless of chitosan content, but in absence of nanoclay, or at higher nanoclay content (3wt\%), there was a remarked difference in WVTR values, when the chitosan composition in the film was varied. As expected, the weight of all cups increased during the 5-day sorption experiment, due to the absorption of moisture from the surrounding environment (inside a desiccator chamber conditioned at $70 \% \mathrm{RH}$ and $37^{\circ} \mathrm{C}$ ), but the total amount of moisture absorbed was different, depending on the film composition. 


\section{Water sorption behavior}

The water sorption behavior of the films prepared were investigated by monitoring the water vapor exchange up to 5 days, in films prepared using $2 \mathrm{wt} \%$ chitosan and increasing concentration of nanoclay (from 0 up to $3 \mathrm{wt} \%$ ). As indicated in figure 7 , the films prepared using chitosan alone $(0 \%$ nanoclay) were damaged (ruptured) during the 5-day experiment, as pointed out by black arrows on the left-side photo (Figure 7a). On the other hands, films containing nanoclay (either 1 or $3 \mathrm{wt} \%$ ) resisted well (without breaking or defects, upon visual analysis) during the WVP experiment. These results support the hypothesis that the inclusion of highly dense nanoclay particles in the polymeric film composition results in strengthened films with enhanced gas barrier properties.

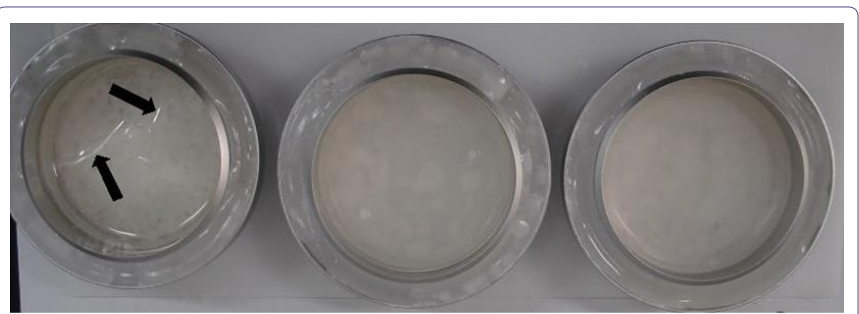
(a) $\mathrm{NB}_{0} \mathrm{CM}_{2}$
(b) $\mathrm{NB}_{1} \mathrm{CM}_{2}$
(c) $\mathrm{NB}_{3} \mathrm{CM}_{2}$

\section{Increasing nanoclay content}

Figure 7: Appearance of composite films during water vapor permeability tests (upon 5 days). Film codes: (a) $\mathrm{NB}_{3} \mathrm{CM}_{2}$ (nanoclay $3 \mathrm{wt} \%$; chitosan $2 \mathrm{wt} \%$ ); (b) $\mathrm{NB}_{1} \mathrm{CM}_{2}$ (nanoclay $1 \mathrm{wt} \%$; chitosan $2 \mathrm{wt} \%$ ); (c) $\mathrm{NB}_{0} \mathrm{CM}_{2}(0 \%$ nanoclay; chitosan $2 \mathrm{wt} \%)$.

\section{Tensile strength}

In order to elucidate the mechanical properties of the composite films prepared, their Tensile Strength (TS) was measured as an indicator of elasticity and strength. As depicted in figure 5, the TS was higher in case of composite films (containing either 1 or $3 \mathrm{wt} \%$ nanoclay, in addition to chitosan), as compared to film samples prepared using chitosan alone regardless of the chitosan content (either 2 or $3 \mathrm{wt} \%$ ). Moreover, the addition of $1 \mathrm{wt} \%$ nanoclay to the chitosan pre-mixture (2wt\%) resulted in the highest TS among all samples (18 MPa), which may be due to a more uniform distribution of nanoclay onto the chitosan matrix. Nevertheless, further addition of nanoclay (up to $3 \mathrm{wt} \%$ ) resulted in reduced TS. These results are similar to those reported by Thanpitcha et al., [26], while preparing film blends incorporating chitosan and chitin.

\section{Elongation at break point}

Another indicator of the mechanical properties of the composite films prepared, the elongation at break point (E) for different polymer-based film blends was investigated, and the results are presented in figure 8 . Films prepared with chitosan alone (2wt\%) were depicted with the highest E value (25.5\%) among all samples, whereas the addition of nanoclay to the filmogenic mixture resulted in films with lower $\mathrm{E}$ values. These results indicate that the elasticity of the polymer-based films, or in other words their ability to deform, decreased upon addition of bentonite nanoclay to the film composition. This behavior may be the result of fulfilling void spaces in the chitosan matrix by the nanoclay particles arranged in multilayer stacks (Figure 4). Moreover, low E values may indicate brittleness and minimum elasticity in the composite films, which has been also reported by Bourtoom [2]. However, according to those

authors, films presenting low E values may have considerably reduced permeability and mechanical properties.

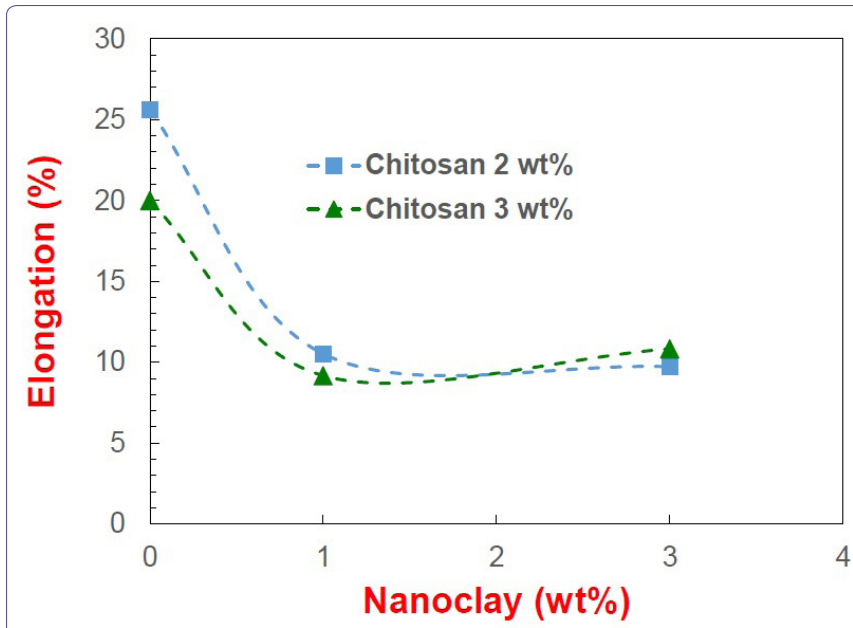

Figure 8: Elongation at break point $(\mathrm{E} \%)$ of the composite films prepared.

\section{Morphological analyses of composite films}

Figure 9 depicts the surface microstructure of chitosan-nanoclay based films at different compositions. In general, these micrographs indicate that the films produced in this study have a nearly smooth surface, with a slight roughness and porous texture, especially when higher concentrations of nanoclay (up to $3 \mathrm{wt} \%$ ) are used in the filmogenic mixture. Seemingly, those films (containing more nanoclay particles) were more thick (nearly $70 \mu \mathrm{m}$, in case of films prepared using $3 \mathrm{wt} \%$ chitosan and $3 \mathrm{wt} \%$ nanoclay, as indicated in table 1 ).

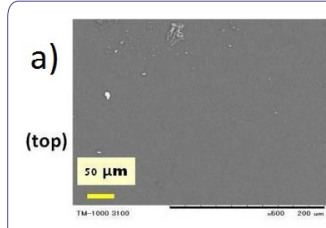

$\mathrm{NB}_{0} \mathrm{CM}_{2}$

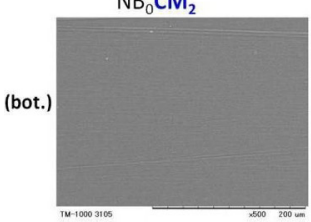

b)

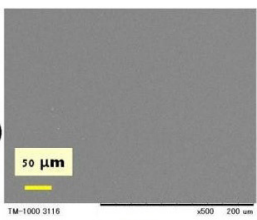

$\mathrm{NB}_{0} \mathrm{CM}_{3}$

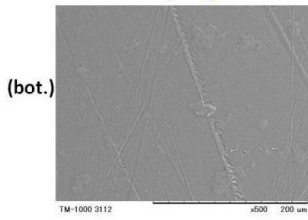

Figure 9: Scanning electron micrographs of the composite films prepared using different chitosan concentrations: (a) $2 w t \%$, or (b) $3 w t \%$.

Left-side photos: No nanoclay. Photos in the Center: $1 \mathrm{wt} \%$ nanoclay.

Right-side photos: $3 w t \%$ nanoclay. $\mathrm{N}=2$ repetitions (top and bottom photos) The film codes are described at figure 7 caption. 
In this study, the casted films containing bentonite nanoclay presented rougher surface, as compared to those with pure chitosan (0wt\% nanoclay), as depicted in films $\mathrm{NB}_{0} \mathrm{CM}_{2}$ and $\mathrm{NB}_{0} \mathrm{CM}_{3}$ (left-side photos, figure $9 \mathrm{a}$ and $\mathrm{b}$ ). This increasing surface roughness, as depicted in films $\mathrm{NB}_{1} \mathrm{CM}_{2}, \mathrm{NB}_{1} \mathrm{CM}_{3}$ (central photos, figure 9a and $\mathrm{b}$ ), and even more in case of films $\mathrm{NB}_{3} \mathrm{CM}_{2}$ and $\mathrm{NB}_{3} \mathrm{CM}_{3}$ (right-side photos, figure $9 \mathrm{a}$ and $\mathrm{b}$ ), may be attributed to the presence of bentonite nanoclay. In fact, up to $3 \mathrm{wt} \%$ of nanoclay particles may disperse well in the clay solution (please refer to figure 1 for details about the experimental procedure), but upon addition to the chitosan acidic solution, nanoclay particles were not completely dissolved in the filmogenic mixture, unlike chitosan. The findings in this experiment agrees well with those in the literature [20,27], which reported that the surface of pure chitosan films presents a smooth, continuous and compact structure. The increased surface roughness, which was likely caused by the addition of small amounts of nanoclay in the film composition, has been also reported by $\mathrm{Xu}$ et al., [28].

Nevertheless, in order to characterize the structure of the films casted in this study, and provide basis for belief whether the films produced here consist of materials within the micro/nanometer size range, asides from scanning electron microscopy further analyses using different techniques, such as X-Ray Diffraction (XRD) analysis, differential scanning calorimetry, and/or thermogravimetric analyses may be desirable. For instance, regarding XRD analysis, this is a powerful method used to investigate crystalline structures, whether looking into the size of the crystals embedded in the micro/nanostructure, as well as their atomic arrangement. The authors have used this technique in a previous study, while developing substitute materials for bone graft implants [29]. Fereydoon et al., [30] have used $\mathrm{XRD}$ analysis to characterize the crystalline structure of cast films of nylon and its nanocomposite with $4 \%$ clay. Other research groups focusing on the development of chitosan-based films have also made use of this technique in order to characterize comprehensively their casted films $[18,19]$.

We demonstrated that tuning the composition of the filmogenic mixture prior to casting enabled us to control the water vapor exchange through the films produced. More specifically, the addition of up to $3 \%$ bentonite nanoclay in the mixture (originally containing $2 \mathrm{wt} \%$ chitosan alone) resulted in a reduction of more than $50 \%$ in the WVP (Figure 6). Controlling gas exchange is essential for enhancing the gas barrier properties of the films developed foreseeing their application as packaging material for fresh food products. Nevertheless, considering that other gases (e.g., oxygen, $\mathrm{CO}_{2}$ ) also play major roles during the storage of fresh food products, other analyses such as investigating the oxygen transmission rate is advisable, in order to fully understand the gas barrier properties of the films developed in this study. In fact, the authors have already performed such analyses when developing zein-based films [4,22].

\section{Conclusion}

Different film blends consisting of chitosan-nanoclay composite were prepared, and the effects of film composition on the water vapor permeability, water vapor transmission, mechanical properties and morphological characteristics of the composite films were evaluated. We demonstrated that the gas barrier properties of polymer-based films can be modulated by tuning the film composition, especially regarding the exchange of water vapor which was effectively reduced by incorporating nanoclay onto the filmogenic mixture. The addition of nanoclay particles to the film blend also resulted in more resistant films (higher tensile strength values) and lower elongation, compared to films prepared using chitosan alone, which may be the result of fulfilling void spaces in the chitosan matrix by nanoclay particles arranged in multilayer stacks. These results support the hypothesis that the inclusion of highly dense nanoclay particles in the polymeric film composition results in strengthened films with enhanced gas barrier properties, as compared to films composed by chitosan alone.

Further developments of such natural polymer-based composite films could find applications such as active packaging system, whereas asides from extending the shelf- life of food materials, the packaging itself could contribute to the safety, e.g., by incorporating antimicrobial compounds onto the film, while assuring the food quality.

\section{Acknowledgment}

The author MA Neves is thankful to the Program to Disseminate Tenure Tracking System, University of Tsukuba, Japan, for the partial support to this research. This study was partially supported by the Japan Society for the Promotion of Science (JSPS) KAKENHI Grant Number 15K07452, Japan. The authors are grateful to Dr. Hiroshi Okadome, Head of the Food Processing Laboratory, National Food Research Institute (NFRI), Tsukuba, Japan, for the much-appreciated support to this research.

\section{References}

1. Rhim JW, Ng PK (2007) Natural biopolymer-based nanocomposite films for packaging applications. Crit Rev Food Sci Nutr 47: 411-433.

2. Bourtoom T (2008) Edible films and coatings: characteristics and properties. Int Food Res 15: 237-348.

3. Krochta JM, De Mulder-Johnson C (1997) Edible and biodegradable polymer films: challenges and opportunities. Food Technol 51: 61-64.

4. Yoshino T, Isobe S, Maekawa T (2000) Physical Evaluation of Pure Zein Films by Atomic Force Microscopy and Thermal Mechanical Analysis. JAOCS 77: 699-704.

5. Arvanitoyannis IS (1999) Totally and partially biodegradable polymer blends based on natural and synthetic macromolecules: Preparation, physical properties, and potential as food packaging materials. J Macromolec Sci 39: 205271.

6. Tharanathan RN, Kittur FS (2003) Chitin--the undisputed biomolecule of great potential. Crit Rev Food Sci Nutr 43: 61-87.

7. Cha DS, Chinnan MS (2004) Biopolymer-based antimicrobial packaging: a review. Crit Rev Food Sci Nutr 44: 223-237.

8. Ribeiro C, Vicente A, Teixeira JA, Miranda C (2007) Optimization of edible coating composition to retard strawberry fruit senescence. Postharvest Biol Technol 44: 63-70.

9. Dutta J, Tripathi S, Dutta PK (2012) Progress in antimicrobial activities of chitin, chitosan and its oligosaccharides: a systematic study needs for food applications. Food Sci Technol Int 18: 3-34.

10. Tripathi S, Mehrotra GK, Dutta PK (2009) Physicochemical and bioactivity of cross-linked chitosan-PVA film for food packaging applications. Int J Biol Macromol 45: 372-376.

11. Neves MA, Hashemi J, Prentice C (2015) Development of novel bioactives delivery systems by micro/nanotechnology. Curr Opin Food Sci 1: 7-12.

12. Tripathi S, Mehrotra GK, Dutta PK (2010) Preparation and physicochemical evaluation of chitosan/poly(vinyl alcohol)/pectin ternary film for food-packaging applications. Carbohyd Polym 79: 711-716.

13. Dutta PK, Tripathi S, Mehrotra GK, Dutta J (2009) Perspectives for chitosan based antimicrobial films in food applications. Food Chem 114: 1173-1182. 
14. Mitelut AC, Tanase EE, Popa VI, Popa ME (2015) Sustainable alternative for food packaging: Chitosan biopolymer - a review. Agro Lif Sc J 4: 52-61.

15. Kim KW, Thomas RL, Lee C, Park HJ (2003) Antimicrobial activity of native chitosan, degraded chitosan, and O-carboxymethylated chitosan. J Food Prot 66: 1495-1498

16. Elsabee MZ, Abdou ES (2013) Chitosan based edible films and coatings: review. Mater Sci Eng C Mater Biol Appl 33: 1819-1841.

17. Morgan AB (2007) Polymer-Clay Nanocomposites: Design and Application of Multi-Functional Materials. Material Matters 2: 20-22.

18. Casariego A, Souza BWS, Cerqueira MA, Teixeira JA, Cruz L, et al. (2009) Chitosan/clay films' properties as affected by biopolymer and clay micro/ nanoparticles' concentrations. Food Hydrocolloid 23: 1895-1902.

19. Souza BWS, Cerqueira MA, Martins JT, Casariego A, Teixeira JA, et al. (2010) Influence of electric fields on the structure of chitosan edible coatings. Food Hydrocolloid 24: 330-335

20. Vargas M, Albors A, Chiralt A, González-Martínez C (2009) Characterization of chitosan -oleic acid composite films. Food Hydrocoll 23: 536-547.

21. Bhuvaneshwari S, Sruthi D, Sivasubramanian V, Kalyani N, Sugunabai J (2011) Development and characterization of chitosan film. Int J Eng Res Applic 1: 292-299.

22. Yoshino T, Isobe S, Maekawa T (2002) Influence of Preparation Conditions on the Physical Properties of Zein Films. JAOCS 79: 345-349.
23. Banker GS, Gore AY, Swarbrick J (1966) Water vapour transmission properties of free polymer films. J Pharm Pharmacol 18: 457-466.

24. Luo $Y$, Pan X, Ling $Y$, Wang $X$, Sun $R$ (2014). Facile fabrication of chitosan active film with xylan via direct immersion. Cellulose 21: 1873-1883.

25. Hale O, Funda T (2010) Preparation and barrier properties of chitosan layered silicate nanocomposite films. Macromol Symp 298: 91-98.

26. Thanpitcha T, Sirivat A, Jamieson AM, Rujiravanit R (2006) Preparation and characterization of polyaniline-chitosan blend film. Carbohyd Polym 64: 560568

27. Pinotti A, García M, Martino M, Zaritzky N (2007) Study on microstructure and physical properties of composite films based on chitosan and methylcellulose. Food Hydrocoll 21: 66-72.

28. Xu Y, Ren X, Hanna MA (2006) Chitosan/clay nanocomposite film preparation and characterization. J Appl Polym Sci 99: 1684-1691.

29. Dupoirieux L, Pourquier D, Picot MC, Neves M (2001) Comparative study of three different membranes for guided bone regeneration of rat cranial defects. Int J Oral Maxillofac Surg 30: 58-62.

30. Fereydoon M, Tabatabaei SH, Ajii A (2014) X-ray and Trichroic Infrared Orientation Analyses of Uniaxially Stretched PA6 and MXD6 Nanoclay Composite Films. Macromolecules 47: 2384-2395. 